\title{
Energetic macroscopic representation control method for a hybrid-source energy system including wind, hydrogen, and fuel cell
}

Tiejiang Yuan, Xiaoshun Dong, Xiangping Chen, Wenping Cao, Juan Hu, and Chuang Liu

Citation: Journal of Renewable and Sustainable Energy 10, 043308 (2018); doi: 10.1063/1.5038091

View online: https://doi.org/10.1063/1.5038091

View Table of Contents: http://aip.scitation.org/toc/rse/10/4

Published by the American Institute of Physics

\section{Articles you may be interested in}

Consensus-based distributed economic dispatch incorporating storage optimization and generator ramp-rate constraints in microgrids

Journal of Renewable and Sustainable Energy 10, 045501 (2018); 10.1063/1.5043187

Development of geothermal heat pumps by using environment friendly refrigerants

Journal of Renewable and Sustainable Energy 10, 043901 (2018); 10.1063/1.5023657

Impact of atmospheric stability on X-band and C-band synthetic aperture radar imagery of offshore windpark wakes

Journal of Renewable and Sustainable Energy 10, 043301 (2018); 10.1063/1.5020437

Quantitative characterization of uncertainty levels of intermittent power sources

Journal of Renewable and Sustainable Energy 10, 043304 (2018); 10.1063/1.4985961

Performance optimization of a photovoltaic solar cell-based hybrid system

Journal of Renewable and Sustainable Energy 10, 044702 (2018); 10.1063/1.5028147

In search of the wind energy potential

Journal of Renewable and Sustainable Energy 9, 052301 (2017); 10.1063/1.4999514 


\title{
Energetic macroscopic representation control method for a hybrid-source energy system including wind, hydrogen, and fuel cell
}

\author{
Tiejiang Yuan, ${ }^{1}$ Xiaoshun Dong, ${ }^{2}$ Xiangping Chen, ${ }^{3, a)}$ Wenping Cao, ${ }^{1,4}$ \\ Juan $\mathrm{Hu},{ }^{5}$ and Chuang Liu ${ }^{6}$ \\ ${ }^{1}$ School of Electrical Engineering, Dalian University of Technology, Dalian 116024, \\ People's Republic of China \\ ${ }^{2}$ Urumqi Electric Power Company, SGCC, Urumqi 830011, People's Republic of China \\ ${ }^{3}$ School of Electrical Engineering, Guizhou University, Guiyang 550025, \\ People's Republic of China \\ ${ }^{4}$ School of Applied Science and Engineering, Aston University, Birmingham B4 7ET, \\ United Kingdom \\ ${ }^{5}$ China Electric Power Research Institute, Beijing 100192, People's Republic of China \\ ${ }^{6}$ Northeast Electric Power University, Jilin 132012, People's Republic of China
}

(Received 1 May 2018; accepted 14 July 2018; published online 7 August 2018)

This paper proposes a new control method for a hybrid energy system. A wind turbine, a hydrogen energy storage system, and a proton exchange membrane fuel cell are utilized in the system to balance the load and supply. The system is modeled in MATLAB/Simulink and is controlled by an improved energetic macroscopic representation (EMR) method in order to match the load profile with wind power. The simulation and test results have proved that (1) the proposed system is effective to meet the varying load demand with fluctuating wind power inputs, (2) the hybrid energy storage system can improve the stability and fault-ride-through performance of the system, and (3) the dynamic response of the proposed system is satisfactory to operate with wind turbines, energy storage, and fuel cells under EMR control. Published by AIP Publishing. https://doi.org/10.1063/1.5038091

\section{INTRODUCTION}

It is widely accepted that wind energy is a renewable source of energy which can be utilized economically in large quantities. However, its intermittent characteristics bring about some challenges as a constant power supply is impossible. The unstable power supply will cause a mismatch between supply and demand so that wind power cannot supply base loads. In order to address this issue, an energy storage system is generally needed in the wind power system. ${ }^{1-4}$ Energy storage technologies such as compressed air energy storage (CAES), batteries, and cryogenic energy storage are commonly used in wind energy systems. Reference 5 set up an experimental test rig to validate the feasibility of the proposed small CAES with a wind energy system. Reference 6 analysed the instability issue on the DC bus and load uncertainty in a wind-battery system. Another hybrid energy system consisting of cryogenic carbon capture and wind is discussed in Ref. 7 with an aim to maximise the operating profit. In practice, each of these storage technologies has their merits and limitations. In particular, the high cost of energy storage facilities limits their wide-spread applications. ${ }^{8,9}$ Moreover, hydrogen production and proton exchange membrane fuel cell (PEMFC) technologies provide one alternative solution to the unstable supply from wind power. ${ }^{10,11}$ In terms of control strategy, Ref. 12 uses fuzzy logic control to minimize the operational cost where electricity price, electrical demands, and economic dispatch are considered. A predictive control strategy is applied to a Photovoltaic (PV)/diesel/battery hybrid system for a domestic house with the purpose of

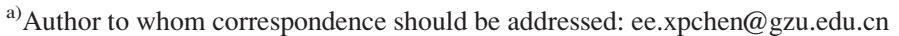


maximizing the use of renewable energy. ${ }^{13}$ An integrated hydro-thermal-wind-solar system is proposed in Ref. 14 under the operation of stochastic programming. With the assistance of a storage system, both the electricity and thermal generation are optimized. Reference 15 compared three optimal operations in a multi-renewable resource micro-grid to minimize the operational costs and emissions. The demand response with load shedding is considered in Ref. 16 to sort out optimal operation for a hybrid renewable system with the uncertainty.

In order to evaluate its effectiveness in a power network, a faithful simulation model is generally required, especially for validation and control purposes. Nonetheless, modeling multiple energy elements with different natures poses a technical challenge. Graphical formalisms are increasingly used to understand multi-physics systems, ${ }^{17}$ such as the bond-graph ${ }^{18}$ energetic macroscopic representation (EMR), ${ }^{19}$ and power-oriented graph. ${ }^{20}$

Among these, the EMR is an effective geometrical modeling tool for multi-source energy systems. It simplifies different energy vectors into four types of elements: energy source, energy accumulation, energy conversion, and energy distribution. The beauty of EMR is to deduct a control structure in a complex system through the inversion analysis of relationships between the components. ${ }^{17}$ The EMR is based on the causal ordering graph. ${ }^{21}$ Reference 22 adopted the EMR method to present forging processes in a simulation environment and validated its effectiveness by experimental results. Reference 23 realized a maximum-power-point-tracking (MPPT) strategy to control a wind energy system through an inversion EMR method. Reference 24 investigated a hybrid energy storage system consisting of fuel cells and batteries. Reference 25 investigated the energy flow in a multi-source energy system. Reference 26 built a wind farm model with the EMR method. Fuel cell systems are also modeled by EMR in Refs. 27-30 to establish an optimal control in the system. However, there are no any reports on a hybrid system combining wind turbines with fuel cells under EMR control. This study develops a new EMR for a hybrid wind-hydrogen-fuel cell system by using electrolyser-PEMFC as an energy storage system and connecting them to a doubly fed induction generator (DFIG) at the DC bus. In this complex system, energy is transferred between three different forms: kinetic energy in a wind turbine; chemical energy in hydrogen, oxygen, and water; and electrical energy in the DFIC and DC bus and converters. After establishing all the components in the multi-physics model, inversed modelling based control loops are deducted in simulation.

\section{THE PROPOSED SYSTEM}

The schematic diagram of the proposed system is shown in Fig. 1. It includes a wind turbine, a DFIG, a rotor-side converter, a grid-connected converter, and an energy storage system. The hybrid energy storage system consists of a hydrogen tank, an oxygen tank, a PEMPC, a water electrolyzer, and DC/DC converters.

In the system, the wind power is converted into mechanical power $\left(p_{m}\right)$ through the wind turbine and then transformed into electrical power $\left(p_{r}\right)$ via the DFIG. The water electrolyser is operated by electricity from the DC bus. In turn, the produced hydrogen and oxygen are collected and stored in the energy storage tanks. When electrical energy is needed, the PEMFC consumes hydrogen and oxygen to generate electrical power $p_{b}$ and supplies it to the DC bus (and then to the grid).

In order to set up the EMR model of the whole system, each component needs to be modelled analytically as given below.

\section{A. Wind turbine}

Let $T_{w}$ be the mechanical torque of the wind turbine. It is calculated as follows: ${ }^{31}$

$$
T_{w}=\frac{\pi \rho C_{p} R^{2} v^{3}}{2 \Omega_{t}},
$$

where $\rho, R, v, \Omega_{t}$, and $C_{p}$ represent the air density, the blade radius of the wind turbine, the wind speed, the angular velocity, and the utilization factor of wind energy, respectively. 


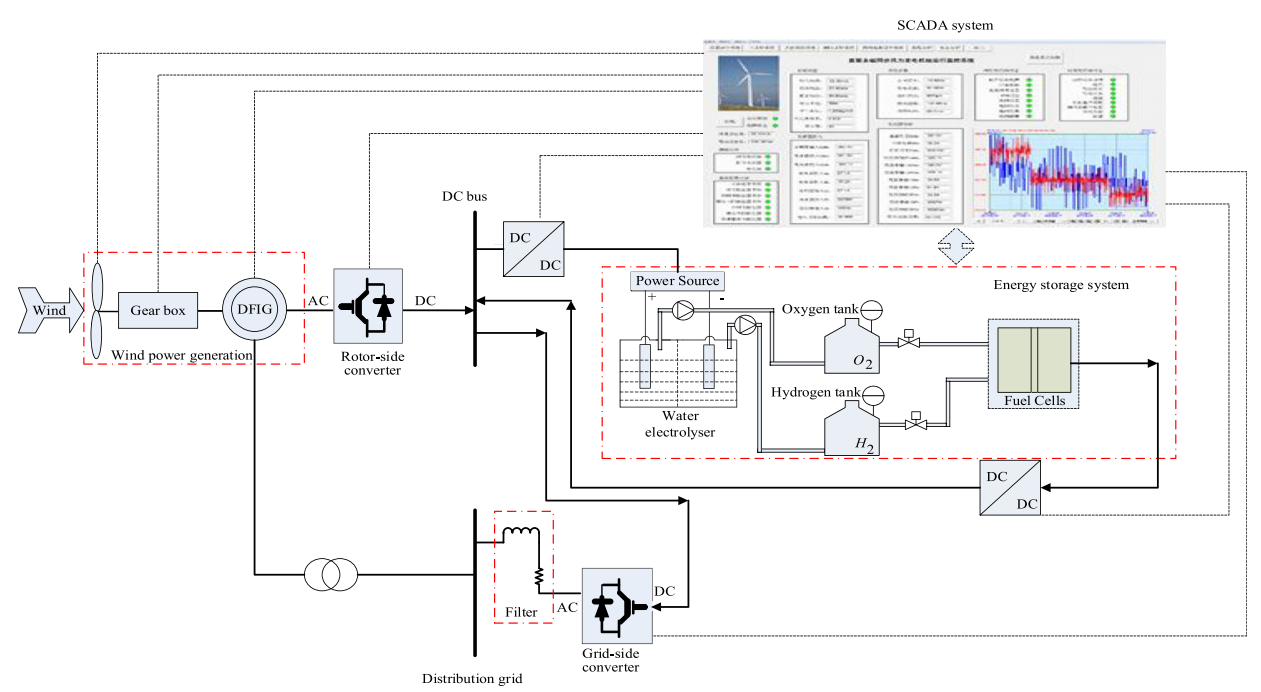

FIG. 1. Schematic diagram of the proposed system.

\section{B. Mechanical drive train}

A mechanical drive train linking the turbine with the DFIG rotor can be expressed as follows: ${ }^{32}$

$$
J \frac{d \Omega_{t}}{d t}=T_{w}-T_{g}-f \Omega_{t},
$$

where $J, T_{g}$, and $f$ are the mechanical inertia, the input torque of the gear box, and the friction coefficient, respectively.

\section{DFIG}

As an electrical machine, the DFIG converts mechanical energy into electrical energy. Its electromagnetic torque $T_{e m}$ can be described as follows: ${ }^{33}$

$$
T_{e m}=\frac{T_{g}}{G}=p\left(\psi_{s d} \cdot i_{s q}-\psi_{s q} \cdot i_{s d}\right),
$$

where $G, p, \psi_{s d}, \psi_{s q}, i_{s q}$, and $i_{s d}$ refer to the transmission ratio of the gear box, pole pairs of the machine, the $d$-axis flux of the stator, the $q$-axis flux of the stator, the $q$-axis current of the stator, and the $d$-axis current of the stator, respectively.

\section{Converters}

Within a power converter, power switches are controlled by their gate drives in sequence as for a control strategy. A switching function is defined to represent the switch sequence by

$$
S_{i j} \in\{0,1\}, \quad i \in\{1,2,3\}, j \in\{1,2\},
$$

where $\left\{\begin{array}{ll}=0, & \text { switch off } \\ =1, & \text { switch on }\end{array}\right\}$ and $i$ and $j$ are the number of the bridge arm and the number of switching in that arm, respectively.

The switching function $m$ can be expressed as follows: ${ }^{34}$

$$
m=\left[\begin{array}{l}
m_{1} \\
m_{2}
\end{array}\right]=\left[\begin{array}{lll}
1 & 0 & -1 \\
0 & 1 & -1
\end{array}\right]\left[\begin{array}{l}
s_{11} \\
s_{12} \\
s_{13}
\end{array}\right] .
$$


The rotor side converter can be formulated as

$$
\left\{\begin{array}{l}
u_{t}=m U \\
I_{g m}=m^{T} I_{t} .
\end{array}\right.
$$

Similarly, the grid-side converter can also be formulated as

$$
\left\{\begin{array}{l}
u_{r}=m U \\
I_{r m}=m^{T} I_{r},
\end{array}\right.
$$

where $u_{r}, I_{r}, U, I_{r m}, u_{t}, I_{g m}$, and $I_{t}$ refer to the rotor voltage, the rotor current, the DC bus voltage, the current of the rotor side converter, the voltage of the grid-connected converter, the current of the grid-connected converter, and the filter current, respectively.

\section{E. L-C filter}

The capacitor $c$ on the DC bus satisfies the formulation ${ }^{34}$

$$
c \frac{d u}{d t}=I_{r m}-I_{g m} .
$$

The filter can be formulated as

$$
L \frac{d I_{t}}{d t}=u_{t}-R_{t} I_{t}-u_{g}
$$

where $R_{t}$ and $L$ are the resistance and the inductance of the filter.

\section{F. Water electrolyzer}

In a water electrolysis process, a chemical reaction takes place to generate electricity. ${ }^{35}$ The flow rate of the hydrogen production $N_{H_{2}}^{\prime}$ is given by

$$
N_{H_{2}}^{\prime}=\eta_{e} N_{e} \frac{p_{e}}{2 F u_{e}},
$$

where $\eta_{e}, N_{e}, p_{e}$, and $u_{e}$ denote the conversion efficiency, the unit number in the series, the input power, and the input voltage per unit, respectively.

The pressure of the electrolyzer can be given by

$$
P_{\text {sto }}=\frac{R T_{\text {sto }}}{V_{\text {sto }}} N_{\text {sto }}
$$

where $P_{s t o}, T_{\text {sto }}$, and $V_{\text {sto }}$ refer to the pressure, the temperature, and the capacity of the hydrogen storage tank, respectively.

\section{G. Hydrogen and oxygen storage devices}

The input flow rate of hydrogen in the storage tank determines the production rate. If the hydrogen loss (leakage) is ignored in the process, the input flow rate is given by ${ }^{35}$

$$
N_{s t o}\left(t_{0}+\Delta t\right)=\int_{t_{0}}^{t_{0}+\Delta t}\left[N_{H_{2}}^{\prime}(t)-N_{f c}^{\prime}(t)\right] d t+N_{s t o}\left(t_{0}\right),
$$

where $N_{s t o}$ and $N_{f c}^{\prime}$ refer to the input flow rate of the hydrogen tank and hydrogen flow rate consumed by the fuel cell. 


\section{H. Fuel cell}

The unit voltage of a fuel cell can be calculated as follows: ${ }^{36,37}$

$$
\begin{gathered}
U_{e}=U_{\text {nernst }}+U_{\text {ohmic }}-U_{d}, \\
U_{\text {nernst }}=1.229-8.5 \times 10^{-4}(T-298.15)+4.3085 \times 10^{-5} T\left(\ln P_{H_{2}}+0.5 \ln P_{O_{2}}\right), \\
U_{\text {ohmic }}=-I_{f}\left(Z_{m}+0.0003\right), \\
\frac{d U_{d}}{d t}=\frac{I_{f}}{C}-\frac{U_{d}}{C R_{a}}, \\
p_{f c}=n \times U_{e} \times I_{f},
\end{gathered}
$$

where $U_{e}, U_{\text {nernst }}, U_{\text {ohmic }}, U_{d}, C, R_{a} p_{f c}$, and $I_{f}$ refer to the unit voltage of a fuel cell, the opencircuit voltage, the reactance voltage, the equivalent voltage, the equivalent capacitance, the equivalent resistance, the output power, and the current, respectively.

\section{INTEGRATED ENERGY STORAGE SYSTEM}

In this work, the water electrolyser, hydrogen and oxygen tanks, and the PEMFC are included in the storage system to balance the wind power and varying demand. In order to control the system in a convenient and accurate manner, the level of energy storage is evaluated by a compound parameter, which is the equivalent state of the storage $l$ as defined as follows:

$$
l=\frac{\frac{p_{H r}}{p_{H c}} \times V_{H c}+\frac{p_{O r}}{p_{O c}} \times V_{O c}}{V_{H c}+V_{O c}},
$$

where $p_{H r}$ is the residual pressure of the hydrogen tank, $p_{H c}$ is the rated pressure of the hydrogen tank, $p_{O r}$ is the residual pressure of the oxygen tank, and $p_{O c}$ is the rated pressure of oxygen tank. $V_{H c}$ and $V_{O c}$ are the volumes of hydrogen and oxygen tanks, respectively.

Equation (18) can be assessed in three intervals. During the normal operation, $l$ should be within 10\%-90\% $\left(l_{n}\right)$. The upper limit $90 \%\left(l_{\max }\right)$ and the lower limit $10 \%\left(l_{\min }\right)$ are the thresholds (two warning indicators) that should not be violated. Ideally, the amount of hydrogen produced by the electrolyser is equal to that consumed by the fuel cell. The storage system outputs power to assist the wind turbine in meeting the varying demand. However, if the storage level reaches the upper level, the electrolysis will stop producing hydrogen/oxygen. If it reaches the lower level, the electrolysis will kick start automatically. The operational principle of the energy storage system is illustrated in Figs. 2-4. A flow chart is presented in Fig. 2. The power generated from the fuel cell and the hydrogen consumption are defined as $P_{m h g}$ and $N_{m h g}$. The corresponding flow rate of hydrogen $N_{H_{2}}$ and power demand $P_{r e}^{(i)}$ in different storage levels are shown in Fig. 3.

Figure 4 shows the operations under different conditions of the indicator $i(1,2$, or 3$)$. When $\mathrm{i}=1$, the storage level reaches the upper limit and four scenarios will follow up accordingly. When $P_{\mathrm{re}}^{(i)} \in \gamma_{1}$, the wind power is more than the net demand. The action in this case is to send the wind power to the net power (equals to $p_{n e t}$ ) and the reminder to the electrolyser. There are 9 such scenarios in total under consideration, including 2 scenarios for $i=2$ and 3 scenarios for $i=3$.

\section{OPERATION UNDER EMR}

The proposed EMR employs the graphical models to describe the coupling relationships between energy elements and designs the control strategy through inverse-model based control loops. In this hybrid wind-hydrogen-fuel cell energy system, the EMR is to deduct the control 


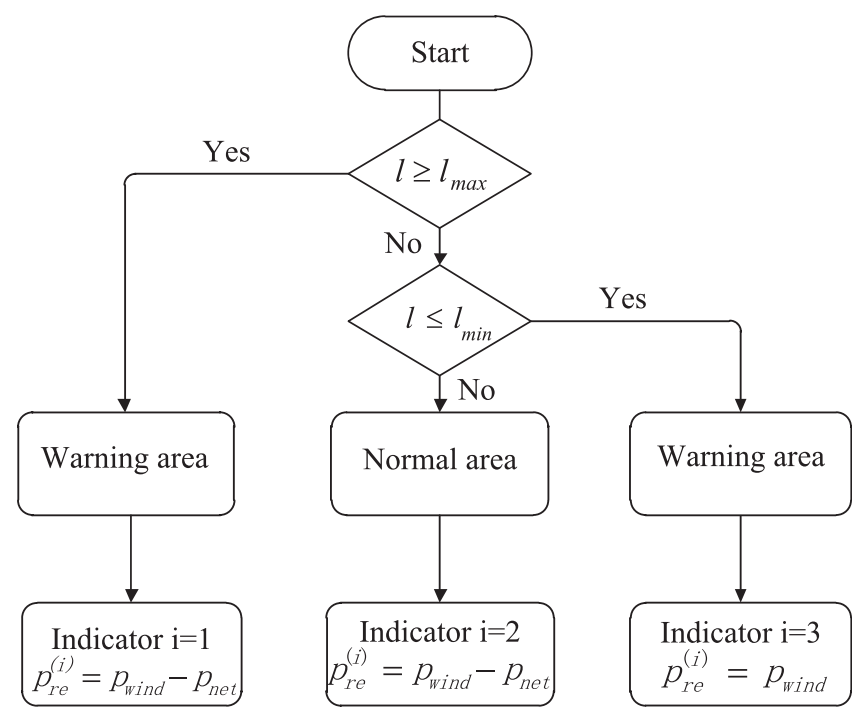

FIG. 2. Principle of operation in the energy storage system.

regulation for controlling energy flow through the energy components. The components in the system can be divided into four types: energy source, energy accumulation, energy conversion, and energy distribution, as shown in Table I.

\section{A. Main parameter chain}

In the EMR scheme, wind energy and the grid are energy sources in the system, while hydrogen/oxygen tanks and the filter are energy accumulation units. The wind turbine, drive train, rotor-side/grid-side converters, water electrolyser, and fuel cells are all energy conversion units. The DFIG is an energy distribution unit. Figure 5 provides the details of the system structure by the EMR scheme.

\section{B. Power flow}

In the system, hydrogen and oxygen are fed into the PEMFC for chemical reaction to generate electricity. The output is DC power and is connected to the DC link for energy exchange. There are four states as for the wind power input. They are three normal operations (wind power higher than net power and wind power lower than net power and equal) and one faulty operation (voltage breakdown), which are shown in the flowchart in Fig. 6.

(1) If the wind power exceeds the set fed-in power to the grid, the hybrid energy storage system absorbs the additional power and uses it for water electrolysis. Hydrogen and oxygen are produced from water and then stored separately in the hydrogen tank and the oxygen tank.

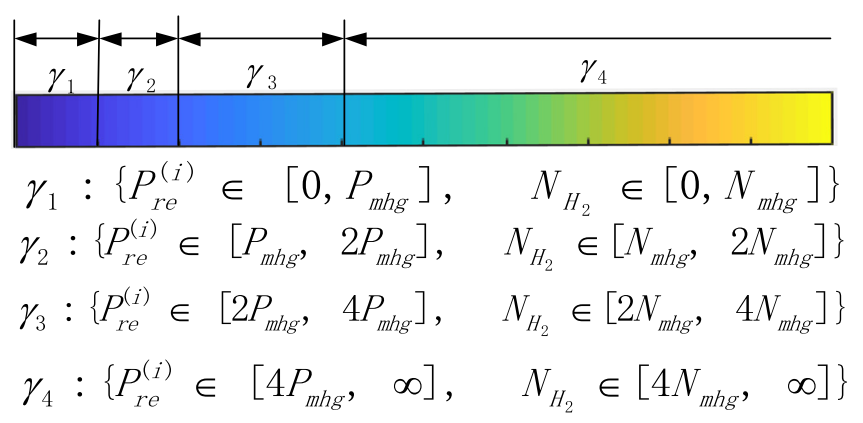

FIG. 3. Interval scheme of power $P_{r e}^{(i)}$ with the flow rate $N_{H_{2}}$. 


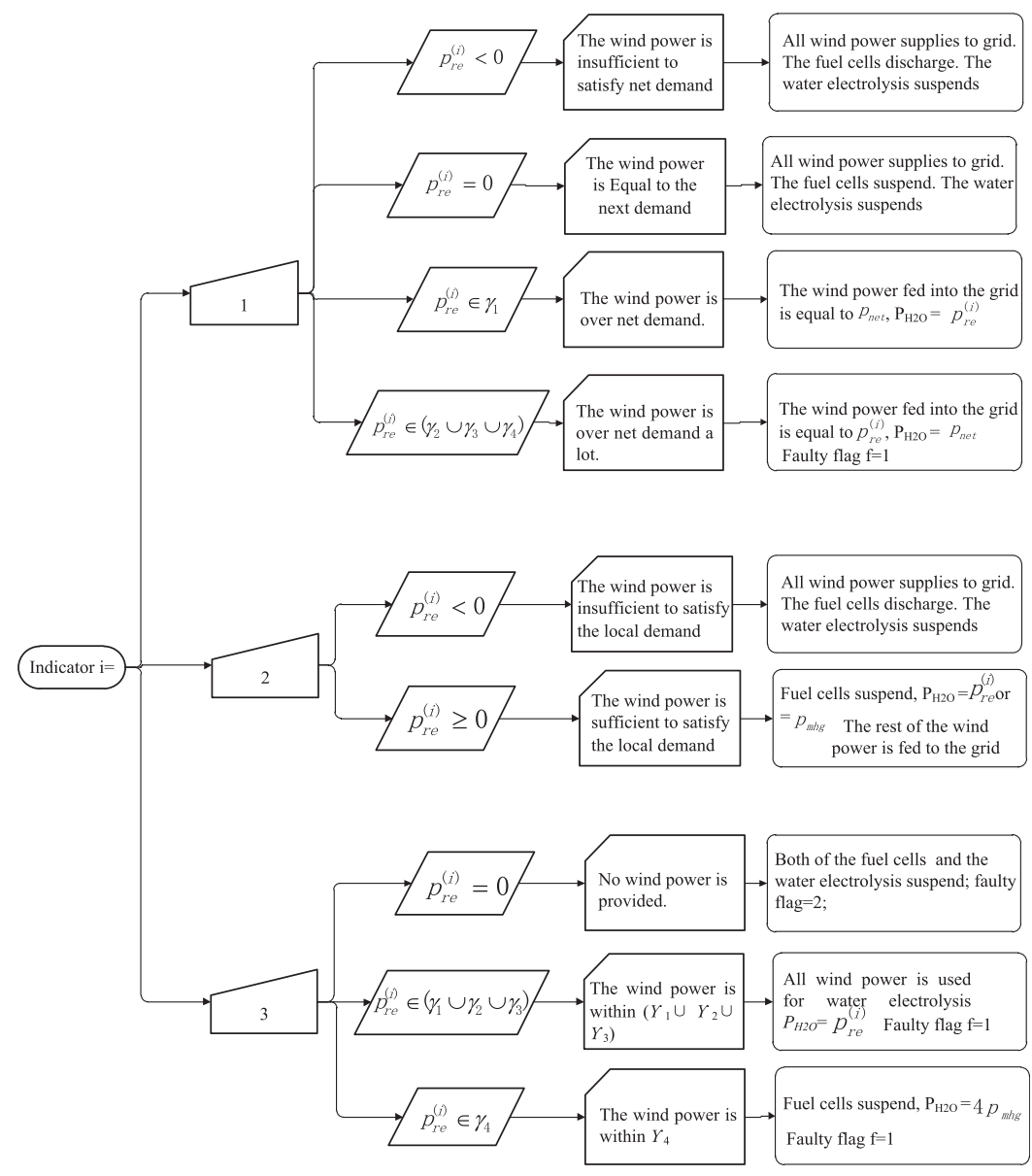

FIG. 4. Nine scenarios and operational schemes of the storage system.

(2) If the actual wind power is less than the set fed-in power to the grid, the stored hydrogen and oxygen are supplied to the fuel cell to generate electricity so as to meet the demand and to support grid stability.

(3) If the actual power is equal to the set one, the water electrolyser and PEMFC standby. The generated wind power is sent to the grid.

(4) If the system is subject to a grid fault, there is insufficient DC power available at the DC bus. The fuel cell then charges the DC-link capacitor. This increases the robustness of the system in terms of low voltage ride-through (LVRT) in the wind energy system.

\section{Control loop of the system}

After developing the EMR scheme, the main parameters in the EMR can be obtained. Figure 7 demonstrates the control loop with an EMR parameter chain in the system.

\section{PERFORMANCE EVALUATION AND DISCUSSION}

Based on the above topology, the system performance is evaluated through experimental tests and three case studies under simulation. Figure 8 illustrates the test in this study. Experimental tests are aimed to assess system performance, while the simulation tests are used to study wind turbine disturbances and grid fault scenarios. On the other hand, the system response for sudden changes in the input or robustness to the fault ride through can be evaluated by simulation. These cases may be limited in the practical operation but easily be realized in modeling and simulation environments. 
TABLE I. Synopses of the EMR.

Wind energy (energy source)




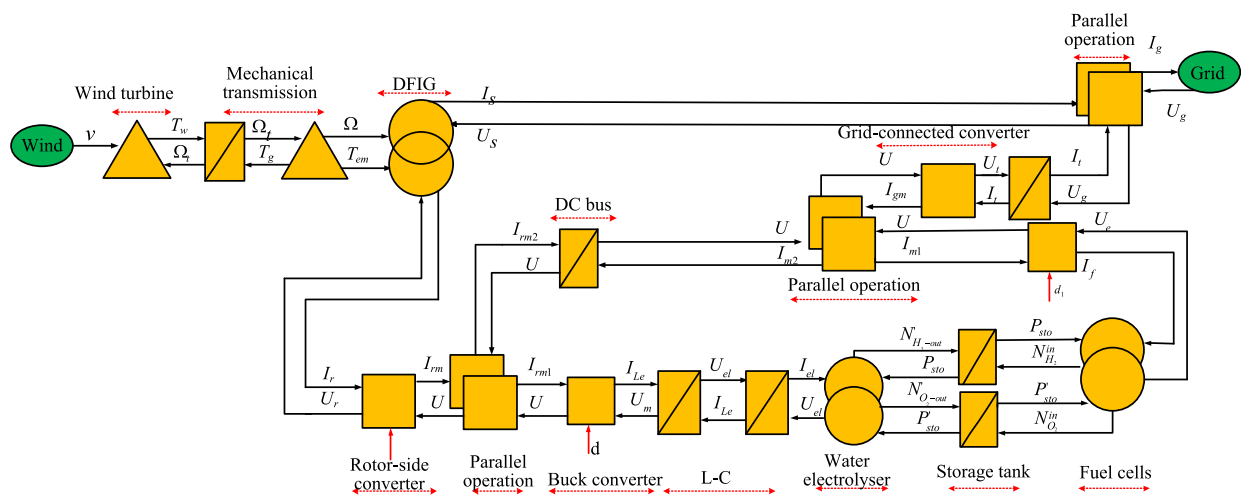

FIG. 5. EMR scheme of the system.

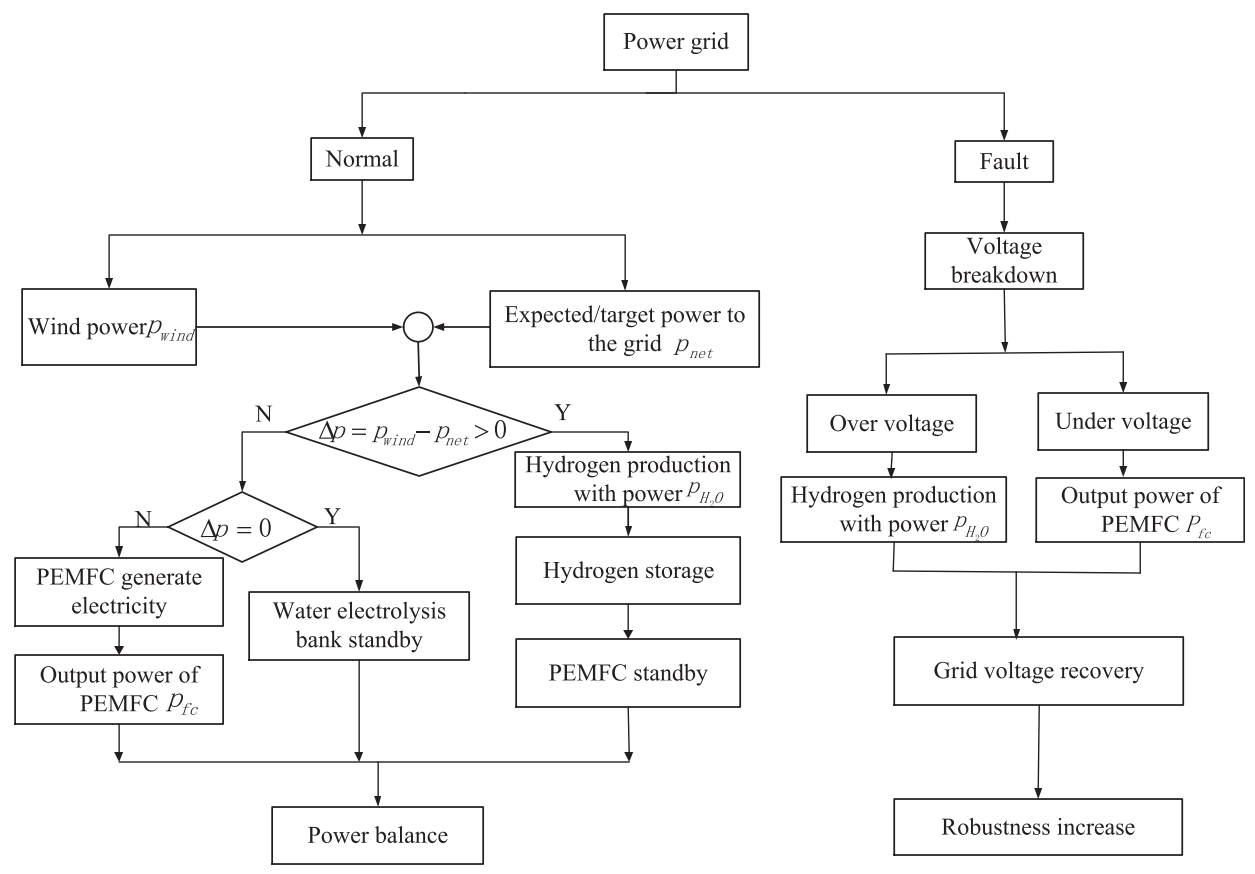

FIG. 6. Flow chart of the EMR working principle.

\section{A. Experimental test}

An experimental test rig is set up, and its photos are shown in Fig. 9. This experimental test rig include a wind turbine with a $3 \mathrm{~kW}$ DFIG, a water electrolyzer with a hydrogen production rate of $1 \mathrm{Nm}^{3} / \mathrm{h}$, a set of $2.5 \mathrm{~kW}$ PEMFC, two hydrogen and oxygen storage tanks with a

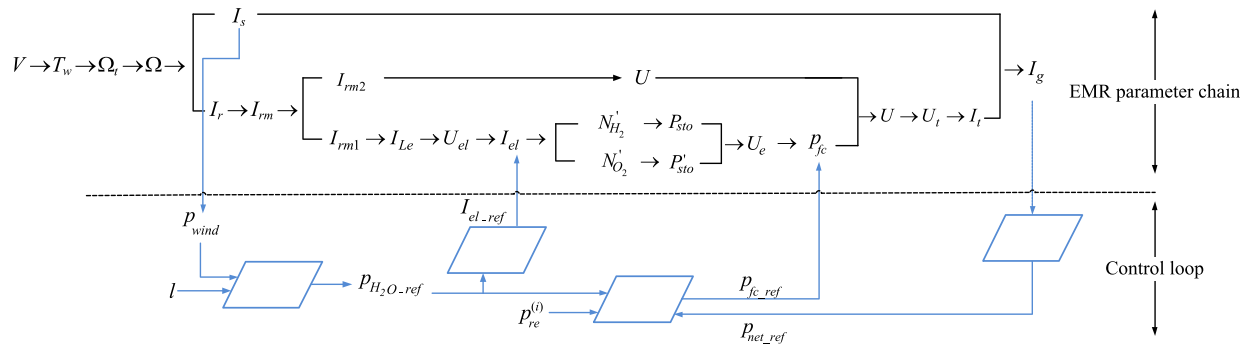

FIG. 7. Control loop and EMR chain of the system. 


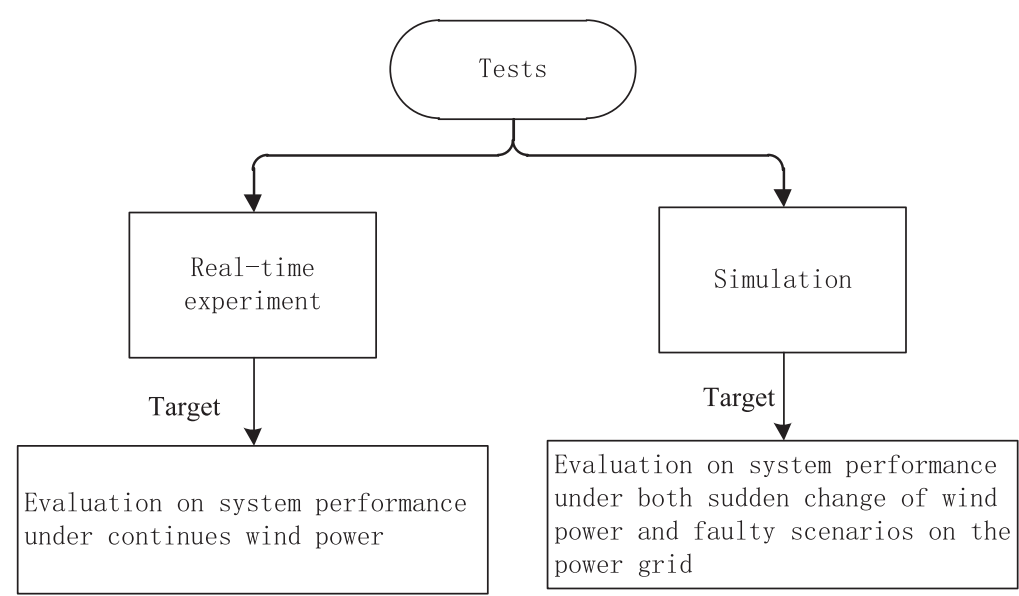

FIG. 8. Experimental arrangement.

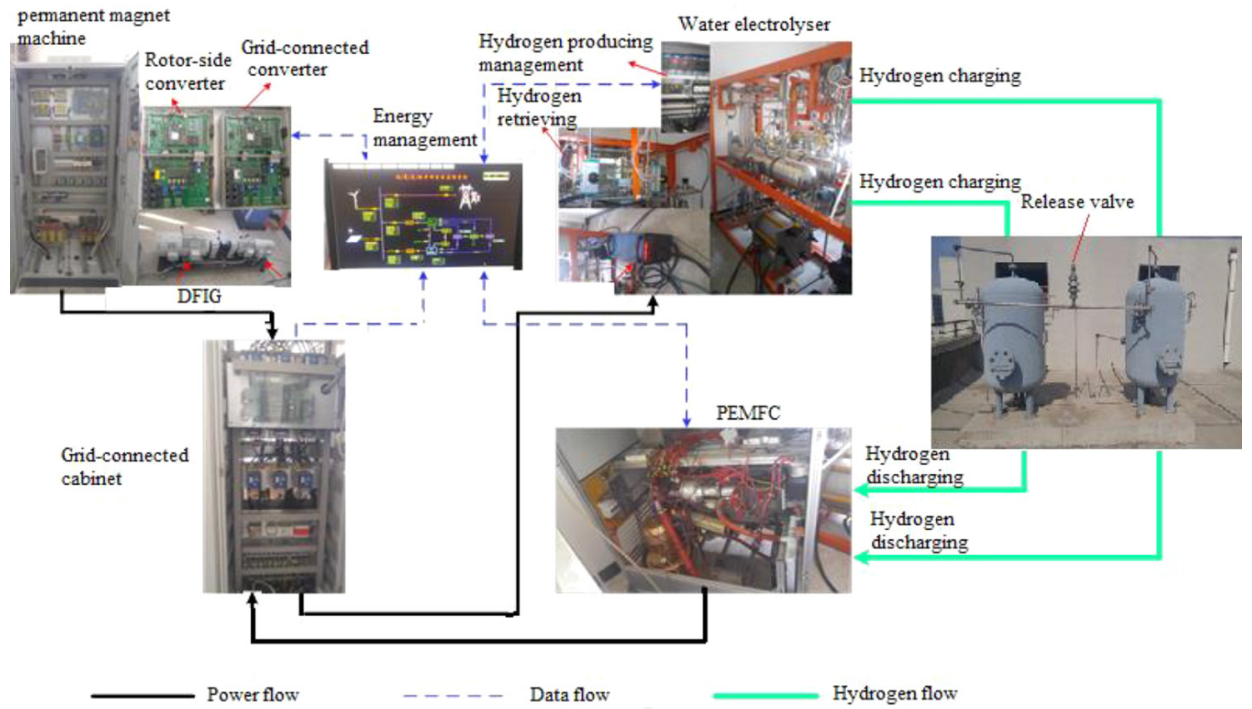

FIG. 9. Experimental test rigs in the laboratory.

column of $5 \mathrm{Nm}^{3}$, two power converters, and a grid-connected cabinet and a control system with energy management.

\section{Wind turbine performance}

A wind turbine test is carried out for a 10-h duration. Figures 10(a)-10(c) present the actual wind speed in $\mathrm{m} / \mathrm{s}$, the turbine speed in rpm, and the output power in Watt. From Fig. 10 , it can be seen that with fluctuating wind speed, the DFIG machine speed is relatively stable around $100 \mathrm{rpm}$. The output power peaks at $3000 \mathrm{~W}$, with a relatively constant output between 2000 and $3000 \mathrm{~W}$.

\section{The water electrolyser}

Figure 11 shows the performance of the electrolyzer over the operational period. Figure 11 shows the DC output power in Watt and the storage level of the tanks. As can be seen, the storage level is reduced significantly after 300 min operation when the demand increases. The generated electricity from water electrolysis assists in wind power to support the grid. 

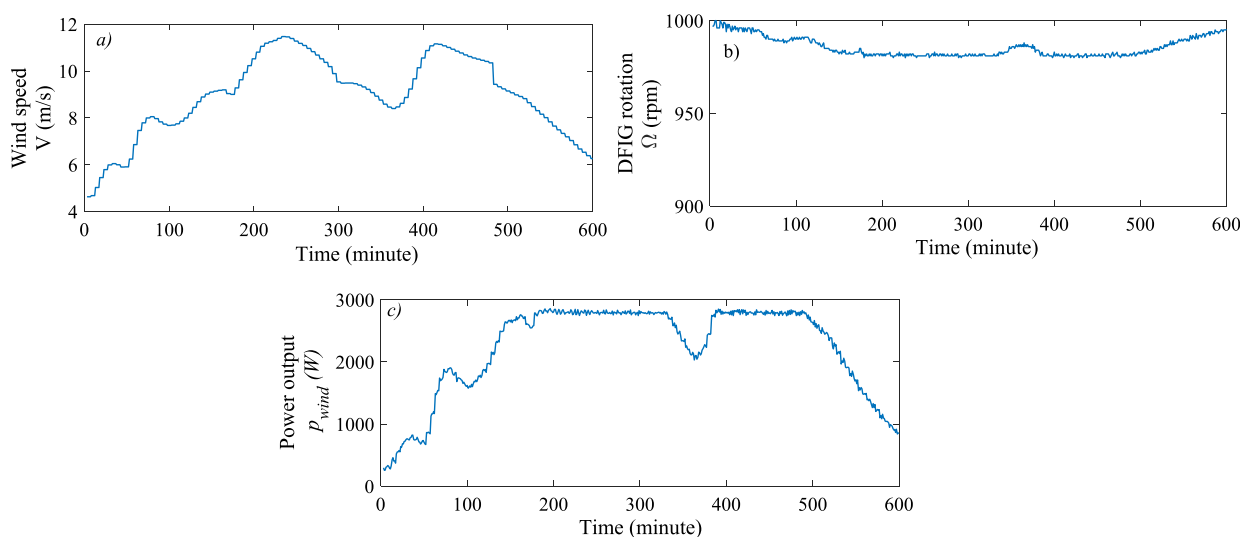

FIG. 10. Wind turbine performance. (a) Wind speed profile. (b) DFIG rotor speed. (c) DFIG output power.
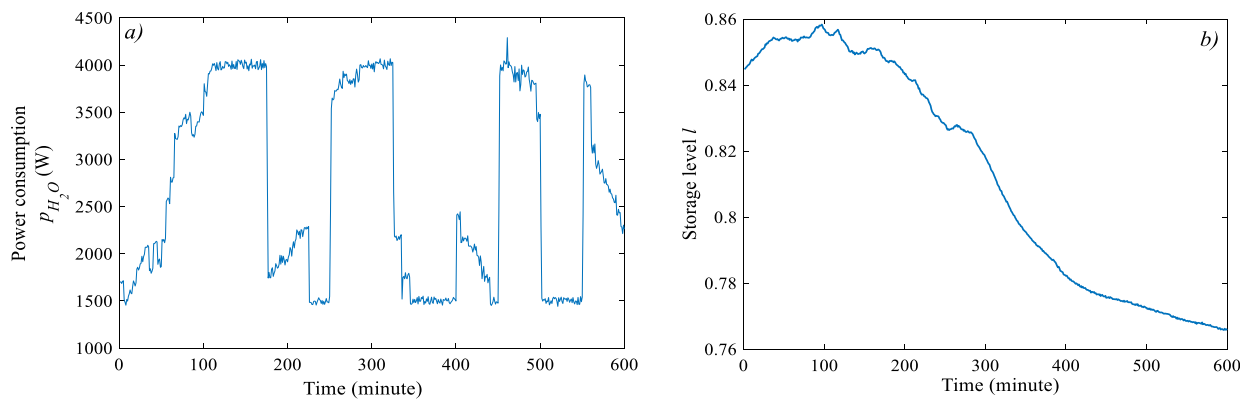

FIG. 11. Performance of the water electrolyzer. (a) Power for the electrolyzer. (b) Storage level.

\section{The fuel cells}

Figure 12 presents the performance of the fuel cells. Figures 12(a), 12(b), 12(c), and 12(d) show the output power in watt, the accumulated hydrogen consumption in mol, the hydrogen filled in $\mathrm{mol} / \mathrm{s}$, and the oxygen filled in $\mathrm{mol} / \mathrm{s}$, respectively.

At $220 \mathrm{~min}$, the fuel cell starts to generate electricity and consumes hydrogen and oxygen. Figure 12(a) indicates the dynamic response of the fuel cell as per the electrical power demand change. The hydrogen and air pressures increase when more hydrogen is fed into the hydrogen tank, as in Fig. 12(b). Figures 12(c) and 12(d) show the changes in hydrogen and oxygen tanks when the fuel cell is operated.
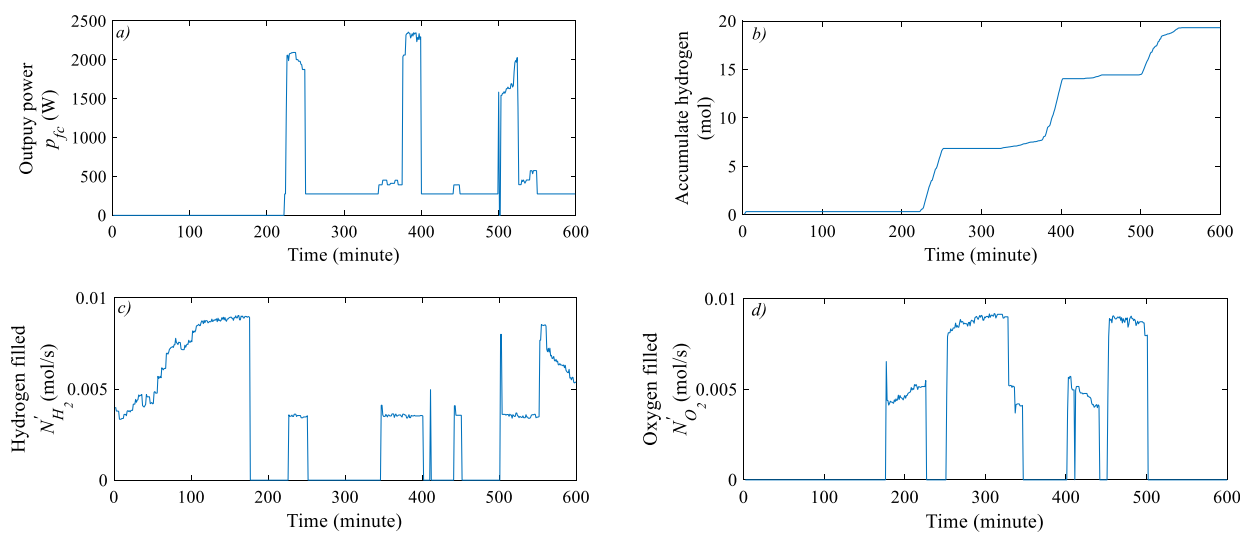

FIG. 12. The performance of the fuel cell. (a) Output power. (b) Accumulated hydrogen consumption. (c) Hydrogen level. (d) Oxygen level. 
TABLE II. Main parameters of the system.

\begin{tabular}{lcc}
\hline \hline Component & Parameter & Value \\
\hline Wind turbine & Air density & $1.225 \mathrm{~kg} / \mathrm{m}^{3}$ \\
& Nominal power of the DFIG & $1.5 \mathrm{MW}$ \\
& Pole pair & 3 \\
& Blade radius of the wind turbine & $32 \mathrm{~m}$ \\
& Nominal voltage & $575 \mathrm{~V}$ \\
& Stator winding resistance & 0.023 p.u. \\
& Stator winding inductance & 0.16 p.u. \\
Fuel cell & Rotor winding resistance & 0.016 p.u. \\
& Membrane & Nafion 115 \\
Others & Initial pressure of the hydrogen tank & 200 pa \\
& Temperature of the electrolysis bath & $25^{\circ} \mathrm{C}$ \\
& Initial pressure of the hydrogen tank & $8 \mathrm{MPa}$ \\
\hline \hline
\end{tabular}

\section{B. Simulation tests}

In order to test the effectiveness and robustness of the proposed system, a system model is established in MATLAB/Simulink with main parameters listed in Table II. Three scenarios are considered in the system. The wind power profile is parameterized, as shown in Fig. 13, and its response is shown in Fig. 14. The actual wind speed from measurements is shown in Fig. 15(a). The third scenario represents a short circuit fault occurred in the transmission line, as shown in Fig. 16(a).

\section{Scenario one}

In the simulation, the target fed-in power to the grid is set at $3500 \mathrm{~W}$. The actual wind power fluctuates between 2500 and $5000 \mathrm{~W}$. Here, a 1-s duration in simulation represents a 15min interval when measurements are taken in reality.

The input power achieves $5000 \mathrm{~W}$ within the first $3 \mathrm{~s}$, then reduces to $3500 \mathrm{~W}$ at $5 \mathrm{~s}$, further decreases to $2500 \mathrm{~W}$ within $2 \mathrm{~s}$, and then increases to $4000 \mathrm{~W}$ at $7 \mathrm{~s}$. This profile is used to study the dynamic response of the storage system as shown in Fig. 13.

Figure 14 shows the performance of the system when the profiles in Fig. 13 are used in the simulation. Within the first $3 \mathrm{~s}$, the surplus wind power is spared for hydrogen production and

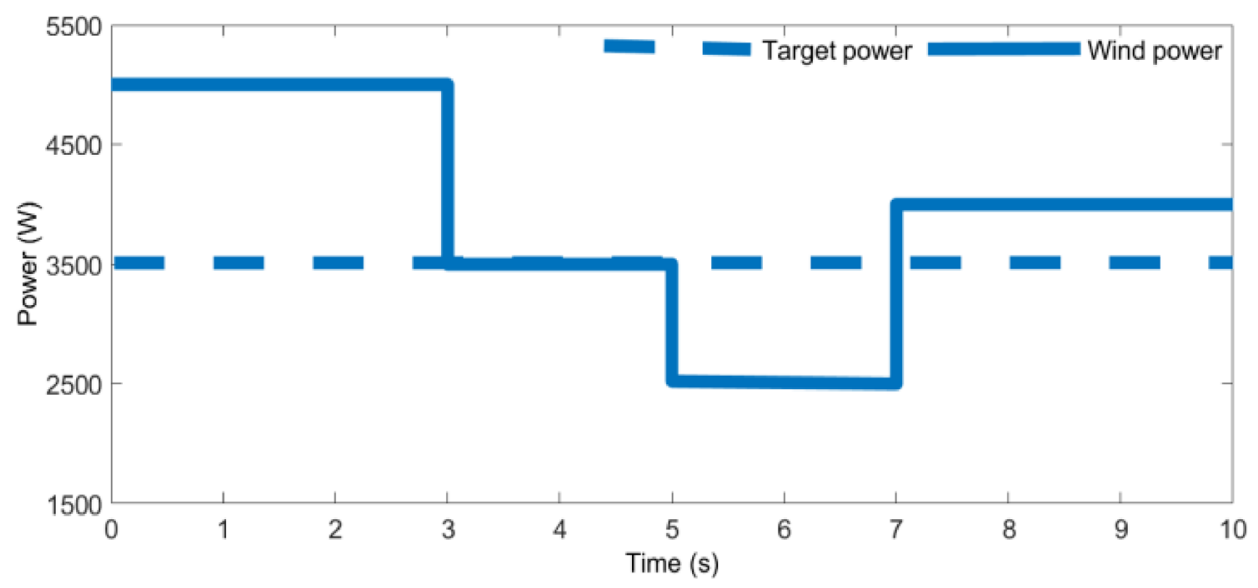

FIG. 13. The profiles of the wind power and grid demands in scenario one. 

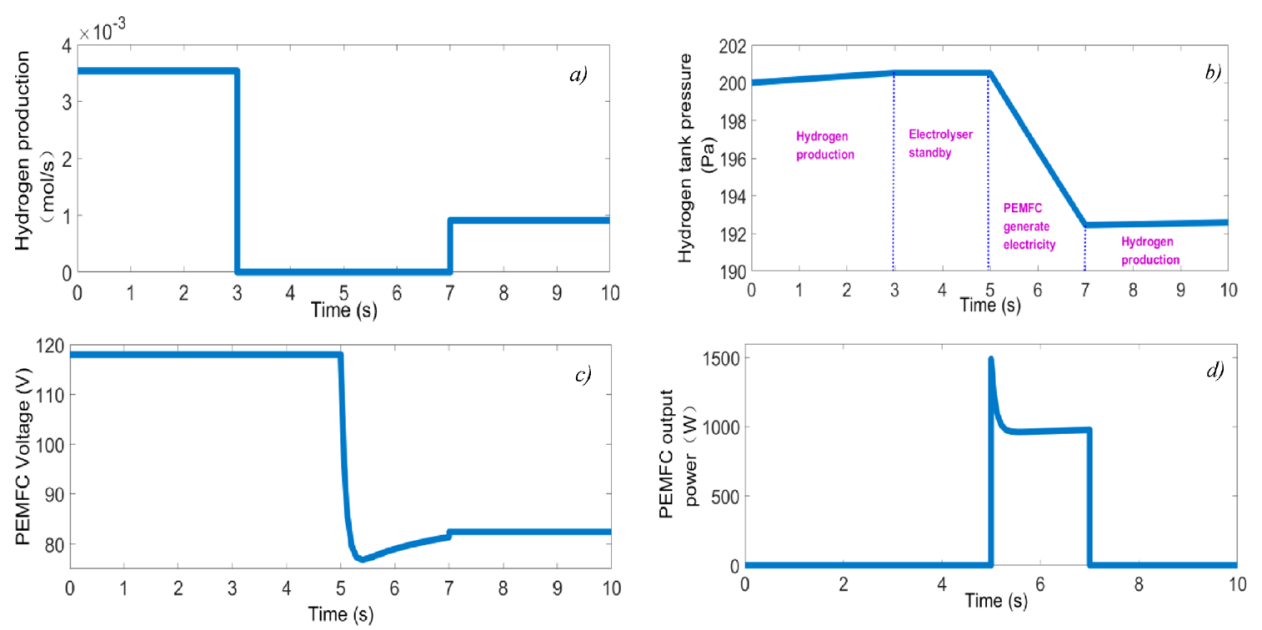

FIG. 14. System performance in scenario one. (a) Hydrogen production. (b) Pressure of the hydrogen tank. (c) The output voltage of the fuel cell. (d) The output power of the fuel cell.

the pressure of the hydrogen tank increases steadily, while the total amount of hydrogen stays at a low level.

The water electrolysis equipment stands by over the next $2 \mathrm{~s}$ when the wind power meets the target power demand. Meanwhile, the hydrogen production decreases from $3.5 \times 10^{-3} \mathrm{~mol} /$ $\mathrm{s}$ to $0 \mathrm{~mol} / \mathrm{s}$ as illustrated in Fig. 14(a). When the wind power reduces (between 5 and $7 \mathrm{~s}$ ), the hydrogen tank pressure decreases as shown in Fig. 14(b). Over the period of 7-10 s, the wind power surges from $3500 \mathrm{~W}$ to $4000 \mathrm{~W}$, while the hydrogen production rises from $0 \mathrm{~mol} / \mathrm{s}$ to 1 $\times 10^{-3} \mathrm{~mol} / \mathrm{s}$. As a result, the tank pressure increases again. The open-circuit output voltage of the fuel cell is given in Fig. 14(c). It can be seen that the terminal voltage is kept at $118 \mathrm{~V}$ until $5 \mathrm{~s}$. From Fig. 14(c), the voltage reduces as the input wind power is below $3500 \mathrm{~W}$. The fuel
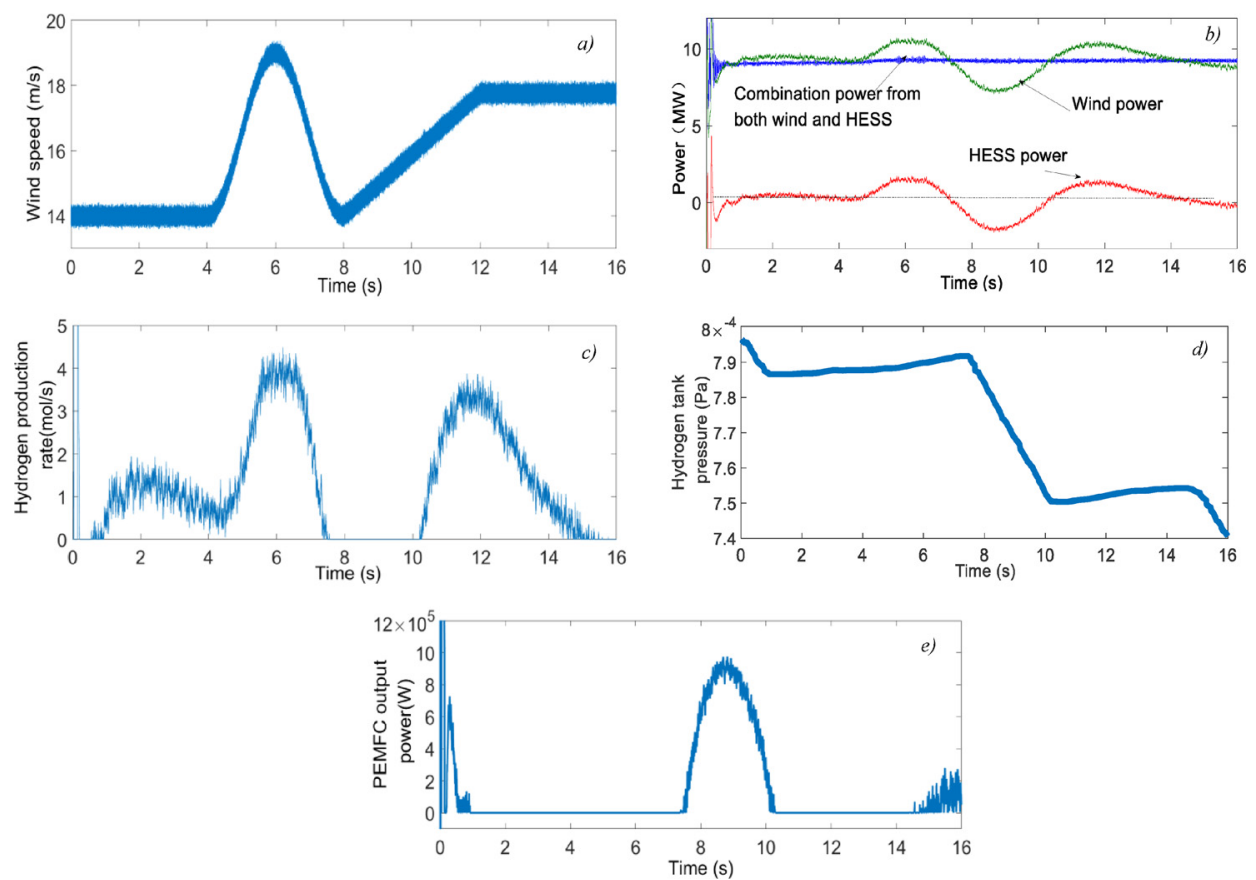

FIG. 15. Profiles in scenario two. (a) Wind speed profile. (b) Power profile. (c) Hydrogen production rate. (d) Pressure profile of the hydrogen tank. (e) Output power of the fuel cell. 

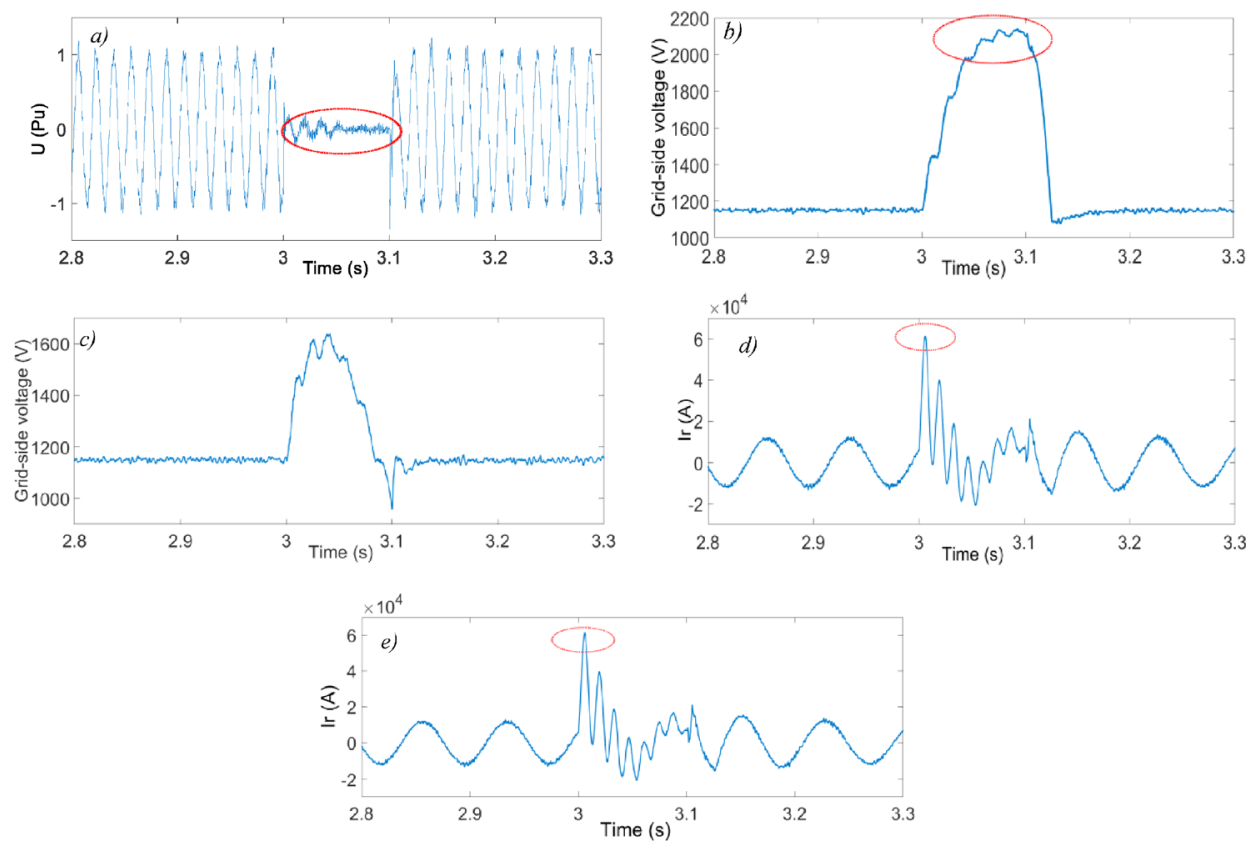

FIG. 16. Parameter profiles in scenario three. (a) Voltage profile of the DFIG. (b) DC voltage on the grid side (without the storage system). (c) DC voltage on the grid side (with the storage system). (d) Rotor current of the DFIG (without the storage system). (e) Rotor current of the DFIG (with the storage system).

cell starts to operate, and the voltage decreases, while the output power prompts to $1000 \mathrm{~W}$ after a minor fluctuation, as shown in Fig. 14(d).

\section{Scenario two}

As can be seen in Fig. 15(a), the wind speed fluctuates between 14 and $19.5 \mathrm{~m} / \mathrm{s}$. The wind power varies between 7 and $10 \mathrm{MW}$ accordingly. The target power is set at $9 \mathrm{MW}$, which is provided by a combination of wind power and PEMFC output power as shown in Fig. 15(b).

Within the first $7 \mathrm{~s}$, the storage system absorbs the extra power from the wind system and carries out water electrolysis to store energy in chemical form. As can be seen from Fig. 15(c), the hydrogen production follows the change in the wind speed, while the pressure of the hydrogen tank slightly increases due to the growth in hydrogen from water electrolysis. From 7 to 10 $\mathrm{s}$, the fuel cell starts to generate electricity by using the hydrogen and the oxygen as illustrated in Fig. 15(e). Therefore, the pressure of the hydrogen storage tank decreases as shown in Fig. 15(d).

\section{Scenario three}

The system is stable prior to any grid faults. When a short-circuit fault appears in the transmission line at $3 \mathrm{~s}$ lasting for $100 \mathrm{~ms}$, the stator voltage of the DFIG collapses, as shown in Fig. 16(a). In contrast, the peak voltage of the DC bus goes up from $1150 \mathrm{~V}$ to $2200 \mathrm{~V}$ and the peak rotor current increases significantly (six times the normal currents), as shown in Figs. 16(b) and 16(c). In this case, the wind power cannot be fed into the grid but gives rise to the DC link voltage.

Fortunately, with a storage system in place, the increase in the rotor current is insignificant where its peak is reduced to 4 times the rated value and the peak voltage decreases from $2200 \mathrm{~V}$ to $1600 \mathrm{~V}$, as illustrated in Figs. 16(d) and 16(e). This proves the effectiveness of the storage system in reducing the severity level of the fault. 


\section{CONCLUSIONS AND FUTURE WORK}

This paper has presented a novel hybrid energy system containing a wind turbine, an energy storage system, power converters, and a PEMFC. The novelty lies in a new energetic microscopic representation (EMR) control method to manipulate energy flow in the complex system according to the energy demand. The wind power is utilized through a DFIG to generate electricity where its stator is connected to the grid and its rotor to the energy storage through a DC link and converters. The water electrolysis is achieved by the proton exchange membrane fuel cell fed from a hydrogen tank and an oxygen tank. The energy storage system is used as an energy buffer to compensate the intermittent wind power input in an attempt to generate a combined input power required by the grid. The system is operated experimentally and also modeled in MATLAB under various operating scenarios. Test results have validated the proposed models and control method. This work is the first attempt to verify the effectiveness of the EMR control method for a wind-hydrogen-fuel cell system. In the future work, an industry scale system will be built and an economic analysis will also be conducted to evaluate the economic benefits of the system and its effect on the grid prices.

\section{ACKNOWLEDGMENTS}

This research was granted by the National Natural Science Foundation of China (Nos. NSFC 51577163 and 51321005) and Xinjiang Science Foundation for Distinguished Young Scholars (2014711005), China.

\section{NOMENCLATURE}

\section{Symbols}

c The capacitance on the DC bus

$C \quad$ The equivalent capacitance of the fuel cells

$C_{p} \quad$ The utilization factor of wind energy

$f \quad$ The friction coefficient of the driven train

$G \quad$ The transmission ratio of the gear box

$i \quad$ Scenario number

$I_{f} \quad$ The current of the fuel cells

$I_{g m} \quad$ The current of the grid-connected converter

$I_{r} \quad$ The rotor voltage

$I_{r m} \quad$ The current of the rotor-connected converter

$i_{s d} \quad$ The $d$-axis current of the stator

$I_{t} \quad$ The filter current

$J \quad$ The mechanical inertia

$l \quad$ The equivalent state of the storage

$L \quad$ The inductance of the filter

$m \quad$ Switching function

$N_{e} \quad$ The number of the electrolyzer unit in the series

$N_{m h g} \quad$ The hydrogen consumption

$N_{\text {sto }} \quad$ The input flow rate of the hydrogen tank

$N_{H_{2}} \quad$ The flow rate of hydrogen consumed by fuel cells

$N_{f c}^{\prime} \quad$ The hydrogen flow rate consumed by the fuel cell

$N_{H_{2}}^{\prime} \quad$ The flow rate of the hydrogen production

$p \quad$ Pole pairs of the machine

$p_{e} \quad$ The inlet power of the electrolyzer

$p_{f c} \quad$ The output power of the fuel cells

$p_{H c} \quad$ The rated pressure of the hydrogen tank

$p_{H r} \quad$ The residual pressure of the hydrogen tank

$P_{m h g} \quad$ The power generated from the fuel cells 
$p_{O c} \quad$ The rated pressure of the oxygen tank

$p_{O r} \quad$ The residual pressure of the oxygen tank

$P_{\text {sto }} \quad$ The pressure of the hydrogen tank

$P_{r e}^{(i)} \quad$ The power demand in scenario $i$

$R \quad$ The radius of the wind turbine blade

$R_{a} \quad$ The equivalent resistance of the fuel cells

$R_{t} \quad$ The resistance of the filter

$S_{i j} \quad$ The switching sequence

$T_{e m} \quad$ The electromagnetic torque

$T_{g} \quad$ The input torque of the gear box

$T_{\text {sto }} \quad$ The temperature of the hydrogen tank

$T_{w} \quad$ The mechanical torque of the wind turbine

$u_{e} \quad$ The input voltage of the electrolyzer per unit

$U_{e} \quad$ The rated voltage of a fuel cell

$U_{n e r n s t}$ The open-circuit voltage of the fuel cell

$U_{\text {ohmic }}$ The reactance voltage of the fuel cell

$u_{r} \quad$ The rotor voltage

$u_{t} \quad$ The voltage of the grid-connected converter

$v \quad$ The wind speed

$V_{H c} \quad$ The volumes of the hydrogen tank

$V_{O c} \quad$ The volume of the oxygen tank

$V_{\text {sto }} \quad$ The capacity of the hydrogen tank

$\rho \quad$ The air density

$\eta_{e} \quad$ The conversion efficiency of the electrolyzer

$\psi_{s d} \quad$ The d-axis flux of the stator

$\psi_{s q} \quad$ The q-axis flux of the stator

$\Omega_{t} \quad$ The angular velocity

\section{Acronyms}

CAES Compressed air energy storage

DFIG Doubly fed induction generator

EMR Energetic macroscopic representation

MPPT Maximum power point tracking

PEMFC Proton exchange membrane fuel cell

SCADA Supervisory control and data acquisition

${ }^{1}$ H. Zhao, Q. Wu, S. Hu, and H. Xu, Appl. Energy 137, 545 (2015).

${ }^{2}$ A. Perera, M. Vahid, D. Mauree, and J. Scartezzini, Appl. Energy 190, 232 (2017).

${ }^{3}$ A. Solomon, D. Kammen, and D. Callaway, Appl. Energy 168, 130 (2016).

${ }^{4}$ J. Shi, Y. J. Tang, L. Ren, J. D. Li, and S. J. Chen, "Application of smes in wind farm to improve voltage stability,"

Physica. C.. Superconductivity. 468(15-20), 2100 (2008).

${ }^{5}$ H. Sun, X. Luo, and J. H. Wang, Appl. Energy 137, 617 (2015).

${ }^{6}$ M. Juan, L. Rojas, R. Dufo-López, and L. José, Appl. Energy 93, 404 (2012).

${ }^{7}$ S. M. Safdarnejad, J. D. Hedengren, and L. L. Baxter, Appl. Energy 149, 354 (2015).

${ }^{8}$ E. Troncoso and M. Newborough, Int. J. Hydrogen Energy 32, 2253 (2007).

${ }^{9}$ D. Anderson and M. Leach, Energy Policy 32, 1603 (2004).

${ }^{10}$ R. A. Patrício, A. D. Sales, and E. M. Sacramento, Int. J. Hydrogen Energy 37, 7355 (2012).

${ }^{11}$ M. Beccali, S. Brunone, and P. Finocchiaro, Appl. Energy 102, 534 (2013).

${ }^{12}$ M. H. Athari and M. M. Ardehali, Renewable Energy 85, 890 (2016).

${ }^{13}$ S. Charfi, N. Brahmi, A. Atieh, and M. Chaabene, J. Renewable Sustainable Energy 10(1), 013502 (2018).

${ }^{14}$ R. Takahashi, H. Kinoshita, and T. Murata, IEEE Trans. Ind. Electron. 57, 485 (2010).

${ }^{15}$ M. Parvizimosaed, F. Farmani, and A. Anvari-Moghaddam, J. Renewable Sustainable Energy 5, 053148 (2013).

${ }^{16}$ F. Conteh, S. Tobaru, and H. Howlader, J. Renewable Sustainable Energy 9(6), 065301 (2017).

${ }^{17}$ L. Horrein, A. Bouscayrol, Y. Cheng, and M. E. Fassi, Energy Convers. Manage. 91, 280 (2015).

${ }^{18}$ A. Vasilyev, J. Andrews, and L. M. Jackson, Int. J. Hydrogen Energy 42, 29406 (2017).

${ }^{19}$ A. Bouscayrol, B. Davat, and B. Fornel, Eur. Phys. J. Appl. Phys. 10, 131 (2000)

${ }^{20}$ R. Zanasi and M. Fei, in Proceedings of European Control Conference (ECC) (2016), pp. 2374-2379. 
${ }^{21}$ G. L. Lopez, R. S. Rodriguez, and M. Victor, Appl. Energy 205, 1478 (2017).

${ }^{22}$ T. H. Nguyen, C. G. Audine, and B. L. Semail, IEEE Trans. Ind. Appl. 50, 244 (2014).

${ }^{23}$ A. Bouscayrol, X. Guillaud, and P. Delarue, IEEE Trans. Ind. Electron. 56, 4826 (2009).

${ }^{24}$ N. Marx, D. Hissel, and F. Gustin, Int. J. Hydrogen Energy 42, 1518 (2017).

${ }^{25}$ A. Tabanjat, M. Becherif, and M. Emziane, Int. J. Hydrogen Energy 40, 2149 (2015).

${ }^{26}$ A. Bouscayrol, P. Delarue, and X. Guillaud, Renewable Energy 30, 2273 (2005).

${ }^{27}$ D. Chrenko, S. Lecoq, and E. Herail, Int. J. Hydrogen Energy 35, 1377 (2010).

${ }^{28}$ L. Boulon, K. Agbossou, and D. Hissel, Renewable Energy 46, 81 (2012).

${ }^{29}$ Z. Jiang and X. Yu, in Power \& Energy Society General Meeting (2009), pp. 1-8.

${ }^{30} \mathrm{C}$. Abbey and G. Joos, IEEE Trans. Ind. Appl. 43, 769 (2007).

${ }^{31}$ R. D. Shukla and R. K. Tripathi, Int. J. Electr. Power Energy Syst. 100, 309 (2018).

${ }^{32}$ B. Boukhezzar and H. Siguerdidjane, Energy Convers. Manage. 50(4), 885 (2009).

${ }^{33}$ A. Uehara et al., IEEE Trans. Energy Convers. 26(2), 550 (2011).

${ }^{34} \mathrm{~L}$. Peng, Y. Li, and B. Francois, in Proceeding in Power Electronics and Motion Control Conference (2009), p. 620.

${ }^{35}$ T. Zhou and B. Francois, Int. J. Hydrogen Energy 34(1), 21 (2009).

${ }^{36}$ K. Agbossou, M. Kolhe, J. Hamelin, and T. K. Bose, IEEE Trans. Energy Convers. 19(3), 633 (2004).

${ }^{37}$ T. Yuan, K. Hu, and Y. Guan, High Voltage Eng. 41(7), 2156-2164 (2015) (in Chinese). 